\title{
JosÉ INÉS SALAZAR, UNA VIDA EN LA FRONTERA \\ DURANTE LA REVOLUCIÓN MEXICANA
}

PEDRO V. SILLER VÁZOUEZ ${ }^{1}$

\section{RESUMEN}

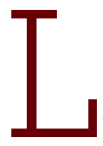
a historia de la Revolución mexicana en el norte de México, ha estado enfocada, quizá de manera muy acentuada, en unos cuantos nombres como el de Villa, Pascual Orozco, los Flores Magón; y otros, como José Inés Salazar, han sido poco estudiados. Al hacerlo, se revela un mundo rebelde mucho más complejo, con raíces profundas en la historia fronteriza, que merece atención para comprender el fenómeno de la rebelión y la violencia norteñas, incluso en su final.

Palabras clave: Chihuahua, Francisco Villa, revolucionarios, magonistas, frontera norte, maderismo.

La noche del 16 de septiembre de 1916, la ciudad de Chihuahua se llenó con tronidos. Muchos pensaron que eran cohetes con los que se continuaba celebrando la fiesta nacional de la Independencia, pero no; eran disparos de armas de fuego provenientes de un grupo encabezado por Francisco Villa, el cual había tenido la audacia de atacar la ciudad con la intención de liberar de la cárcel

1 Profesor-investigador en la Universidad Autónoma de Ciudad Juárez; correo: psiller@ uacj.mx 
a varios personajes, entre ellos, a José Inés Salazar, y se hizo con éxito.

La sorpresa entre las tropas del general Jacinto B. Treviño, que defendían la capital del estado, no podía ser mayor. Unos meses antes, el 9 de marzo, Villa, en un hecho histórico por su audacia, había atacado la población fronteriza de Columbus, Nuevo México, con lo que desató una de las persecuciones más furiosas que recuerde la historia de los dos países. Las noticias lo ubicaban en Sonora; otras, en Coahuila, y muchas lo mencionaban escondido en alguna parte de la sierra chihuahuense, o sea, en cualquier lugar menos en las goteras de la ciudad. Además, todos coincidían (quizá hasta el propio Villa) en que ese grupo de atacantes eran como fantasmas de lo que quedaba del ejército llamado División del Norte y que formalmente se había disuelto en diciembre del año anterior.

Uno de los villistas participante en el ataque, José María Jaurrieta, describe el abrazo entre ambos personajes, seguido del éxito de la acción y la frase de Villa: "Vine porque supe que lo iban a fusilar" (Jaurrieta, 1997, p. 40). El hombre a quien Villa rescató era uno de los guerrilleros más famosos de la zona fronteriza en el norte de México. Una verdadera leyenda. ¿Quién era ese personaje por el que el Centauro del Norte arriesgó la vida?

\section{FUIMOS MAGONISTAS}

La biografía de José Inés Salazar está íntimamente ligada a la franja fronteriza de Chihuahua con sus resentimientos por la pérdida de los territorios mexicanos, ulterior a la guerra del 48: la venta del territorio de La Mesilla, la emigración de trabajadores mexicanos a Texas, Nuevo México y Arizona, y la compra de vastas extensiones de tierras para instalar explotaciones agrícolas, mineras y silvícolas norteamericanas.

Una de ellas fue la región de Casas Grandes, más conocida como el distrito Galeana, una enorme y generosa pradera que forma parte de Chihuahua, Nuevo México y Arizona. Después de la guerra del 48 y de la venta del territorio de La Mesilla, muchos 
mexicanos desplazados se asentaron en esta zona gracias a donaciones del gobierno, y para 1883 vieron con temor la llegada de colonos norteamericanos y mormones, a quienes la administración mexicana les vendió tierras para establecerse y les concedió ventajas aduaneras de las que carecían los nacionales.

En 1896 llegó al distrito Galeana el ferrocarril que unía esta región con Ciudad Juárez, motivo por el que detonó un enorme auge económico y provocó la ambición de muchos grupos de inversionistas norteamericanos, quienes compraron más tierras con ayuda de las autoridades porfiristas, de manera legal o no, y con ello desplazaron a los mexicanos.

Las principales colonias mormonas fueron cinco: Juárez, Dublán, Díaz, Pacheco y Oaxaca. En un inicio, con una cifra de 1386 habitantes y que, dentro de 17 años, o sea, para 1900, se había duplicado. En 1899 el cónsul estadounidense en Ciudad Juárez solicitaba una delegación en Casas Grandes, debido al enorme número de paisanos suyos en la zona. Decía que, además de los mormones establecidos en las colonias y de su rápido crecimiento, había otros 2700 compatriotas en los alrededores de la zona de Casas Grandes y entre 500 y 1000 en las minas y ganadería en las montañas, mientras que el pueblo tendría unos 1500 habitantes mexicanos (1889, rollo 5).

Así, además de la colonización mormona, la región norte de Chihuahua fue invadida por los desarrollos agropecuarios, tales como el de Palomas Land and Cattle Company con 800000 hectáreas; la compañía Corralitos Cattle Company, establecida en 1886 dentro de 500000 hectáreas; al mismo tiempo que explotaba una serie de minas de plata concentradas en la Candelaria Mining Company, entre ellas, la de San Pedro, iniciada por los españoles en 1750 y abandonada a mediados del siglo XIX. La parte ganadera tenía 40000 cabezas de ganado fino (Durham) y 2000 caballos. Los testimonios sobrevivientes afirmaban que en San Pedro Corralitos, se producía todo lo que "se comía, se vestía o se usaba allí". En sus mejores épocas llegó a tener entre 2000 y 3000 trabajadores. Para 1908, la compañía regaba aproximadamente unas 12000 hectáreas en un proyecto que compartía con las colonias mormonas. 
De la misma manera que ellos, en la práctica, los terrenos de la compañía estaban fuera de la jurisdicción de las autoridades del distrito, por lo que tenía sus propios guardias y cárcel, y el gerente se negaba sistemáticamente a dar informes, incluso a los encargados del censo federal. Sus propietarios residían en Nueva York y sus acciones se cotizaban en la Bolsa de Valores. Alrededor de esta propiedad había otras de tamaño semejante: al oeste, colindaba la hacienda Ojitos del inglés Lord Beresford Delaval con 250000 hectáreas y un amplio prestigio por sus animales de alto registro; al norte, con la Palomas Land and Cattle Company; y al sur, con haciendas de Luis Terrazas (El Paso Herald, 1913, p. 3; Paulsen, 1983, p. 255).

Con los anteriores cambios, pueblos como Ascensión, Palomas, Guadalupe y otros tantos en el estado de Chihuahua, hechos por migrantes como resultado del Tratado de Guadalupe-Hidalgo o de la compra de La Mesilla, de nuevo se sentían amenazados por los estadounidenses y sus empresas ganaderas, mineras o forestales. El sentimiento antinorteamericano en la zona fue cada vez mayor.

José Inés Salazar nació en Casas Grandes el 19 de abril de 1889. Hijo de Tomás Salazar y de Petra Martínez. ${ }^{2}$ Se sabe que pasó su infancia y juventud en Casas Grandes. Uno de sus primeros trabajos fue en San Pedro Corralitos, es decir, en la Candelaria Mining Company; enseguida, algunos lo ubicaron en Cananea, además de El Tigre Mining Company de Sonora. Posteriormente, se hizo famoso por su fortaleza y estatura en las minas de Morenci, Arizona. Fue allí donde se unió al grupo de los hermanos Flores Magón -al magonismo-, junto con otros casagrandinos como Manuel y Cenobio Orozco, quienes lo acompañarían durante un buen trecho de sus aventuras (Lloyd, 1987, p. 140).

El magonismo fue una corriente de pensamiento diseminada en las páginas de diferentes periódicos editados en Estados Unidos, principalmente en el Regeneración, en Los Ángeles, California, entre 1906 y 1911. En su primer número incluía un artículo

2 Los libros, folletos y periódicos lo mencionan indistintamente como Inés o Ynes. Reidezel Mendoza encontró su acta de nacimiento en Casas Grandes con la fecha mencionada en su ensayo: “José Inés Salazar, semblanza de un guerrillero", el cual permanece inédito, por lo que le agradezco que me compartiera el dato. 
José Inés Salazar, una Vida en la frontera duRAnte la ReVolución...

con un título sugerente: "La raza muere", un alegato acerca de cómo el trabajo excesivo impuesto por las empresas extranjeras terminaba degenerando a los mexicanos:

El origen de nuestra decadencia fisiológica está en la tiranía. La inmensa mayoría de nuestros compatriotas está condenada a desaparecer por la fatiga, por el hambre, por el maltrato. Las agotantes labores á que están sujetos los trabajadores para obtener el miserable salario que no les alcanza para comer, los debilitan y debilitan á la raza, porque esos hombres tienen hijos, hijos nacidos en la miseria de padres agotados a fuerza de trabajo y de injusticia. Las largas labores dan a la tuberculosis ejércitos compactos encargados de propagar la debilidad y la muerte (Regeneración, febrero de 1906, p. 1).

El impacto de Regeneración sobre los trabajadores como Salazar, fue muy intenso por varias razones. La primera de ellas, porque hablaba de un proletariado como tal, o sea, de quien no tiene más que su fuerza de trabajo para vivir; en segundo lugar, porque continuamente llevaba a cabo encuestas entre los trabajadores para conocer el tipo de artículos que querían leer, las denuncias que deberían hacerse y hablaba de casos en los que fácilmente se reconocían los obreros a sí mismos. Además, desde sus páginas se insistió en que el general Díaz estaba vendiendo el país a los estadounidenses. Como ha señalado Claudio Lomnitz (2010), esa frontera debía ser un umbral mágico en donde se pasaba "de un mundo a otro: no sólo de una lengua a otra, o de una moneda a otra, sino de un mundo de relaciones a otro, de un pueblo a otro, y aun de un tiempo a otro"; al permitirse acciones como las de Cananea, Corralitos o colonias mormonas, se estaba recorriendo hacia el sur con la imposición de condiciones de los anglodominantes, en lo que parecía ser un dominio que no solo era de carácter económico, sino también de tipo racial y cultural. El periódico Regeneración llegó a tirar en sus mejores momentos treinta mil ejemplares semanales, pero su audiencia fue mucho mayor, debido a que se leía en voz alta en plazas públicas de ambos lados de la frontera y en lugares como cafés, cocinas populares y bar- 
berías. Las páginas de Regeneración reflejaron fielmente el drama de miles de mexicanos, tanto recién llegados como herederos del suceso acaecido en 1848, con sus secuelas de violencia por parte de los norteamericanos.

Las primeras noticias de José Inés Salazar dentro del magonismo, se refieren a un documento firmado en Metcalf, Arizona, el 9 de diciembre de 1907, a nombre del club "Santos Degollado" y publicado en el semanario magonista Revolución, en apoyo a Manuel Sarabia, quien había sido secuestrado por los policías norteamericanos y estuvo a punto de ser asesinado (Revolución, 1907, p. 2; Albro, 1969).

El 30 de junio de 1908, en un pequeño poblado fronterizo de nombre Palomas, Chihuahua, aledaño al célebre Columbus, Práxedis G. Guerrero, un joven abogado que había abandonado las promesas de su profesión por dedicarse completamente a la rebelión armada contra Porfirio Díaz, junto con otros simpatizantes, entre ellos, José Inés Salazar y Manuel Orozco, intentaron tomar por sorpresa a la población, pero esta se defendió y resistió los ataques, lo que causó que los revolucionarios se retiraran. Al mes siguiente trataron, también infructuosamente, de tomar Casas Grandes. Esto significa que, a principios de 1908, quizá por la crisis en la minería, el consecuente desempleo y el aumento en las injusticias laborales, estos personajes pasaron de la simple protesta a la lucha armada (Lloyd, 2001, p. 74).

Al interior de México, el 24 de octubre de 1908, Porfirio Díaz declaró públicamente que se presentaría como candidato a las próximas elecciones presidenciales, desmintiendo lo dicho un año antes en la famosa entrevista Díaz-Creelman, por lo cual se intensificaron las llamadas causas de la Revolución mexicana: condiciones internacionales favorables a la revolución por la edad de don Porfirio, aunadas a una división entre las élites políticas que con el tiempo tomó un aspecto irreconciliable y mortal, y un descontento en todo el país, dadas las condiciones económicas de fin del siglo.

En 1909, en vísperas de las elecciones presidenciales que tendrían lugar al año siguiente, apareció el partido Antirreeleccionista encabezado por Francisco I. Madero y el doctor Francisco 
Vázquez Gómez. El primero tenía treinta y siete años, hijo de una familia de enormes recursos económicos, originario de Coahuila, quien, desde unos cinco años antes, había incursionado sin éxito en la política local. El segundo, de cincuenta años, era un médico prestigioso de la capital de la república, de origen muy pobre.

La campaña antirreeleccionista abarcó buena parte del país entre 1909 y 1910, pero, como lo había anunciado la clase política de la época, las elecciones dieron un triunfo rotundo a Díaz, aunque para eso tuviera que encarcelar a Madero y a sus partidarios días antes de las votaciones. Por esto y por la represión que se desató en todo el país, muchos de ellos se levantaron en armas.

\section{EL MADERISMO}

La rebelión proclamada por Madero en su manifiesto fechado el 8 de octubre de 1910 tuvo una amplia repercusión, pero en ningún otro lado tuvo un efecto duradero como en Chihuahua, donde emergió una verdadera insurrección popular. Prácticamente no hubo un solo lugar donde no hubiera, al menos, una pequeña rebelión. En esos estallidos locales, la participación de los magonistas, como la de Salazar, fue fundamental debido a su experiencia desde 1906 y su capacidad para contrabandear armas, difundir propaganda y conseguir adeptos.

Los hechos de armas acaecieron en Chihuahua desde el mismo 20 de noviembre en los alrededores de ciudad Guerrero, encabezados por Pascual Orozco, que llevaron sobre sus hombros el peso de las primeras incursiones militares cuando en el resto del país solamente existieron brotes aislados de violencia que fueron rápidamente acallados, como fue en el caso de Veracruz, Sinaloa, Yucatán o Puebla.

La entrada de Madero a territorio nacional sucedió hasta el 14 de febrero de 1911 y, por una mala coordinación, las tropas de Orozco que habían viajado desde el centro de Chihuahua hasta la frontera y las que se incorporaron ahí a la llegada de Madero, no lograron reunirse, así que Orozco se internó nuevamente a la sierra en espera del líder nacional. 
El primer puerto fronterizo desde donde se inició la marcha maderista, fue en Guadalupe, en la margen del río Bravo, a unos veinte kilómetros al oriente de Ciudad Juárez. Era una pequeña población compuesta por unas ciento cincuenta casas con ochocientos habitantes, cuyo origen emanaba de una migración de mexicanos expulsados en consecuencia de la guerra de 1848. La población había sido tomada días antes por el magonista Prisciliano Silva, a quien se le acababa de unir en este lugar Lázaro Gutiérrez de Lara con unos veintiocho estadounidenses.

Hasta ahí llegó un emisario de Madero con la encomienda de pedirle a Silva que le facilitara unos carros y unos caballos, porque estaban cerca de Zaragoza sin la posibilidad de continuar, y este le envió ocho carros, un coche y veinte caballos bajo la responsabilidad de Gutiérrez de Lara, "como lo exige la hospitalidad y el compañerismo, pues es notorio el mal estado en que se encuentra esa columna, al grado de que se ha estado varios días para recorrer una distancia que se hace en un día" (Bartra, 1990, p. 279). Madero, apoyado por Gutiérrez de Lara, le solicitó a Silva que se uniera a la causa antirreeleccionista y abandonara al magonismo. De acuerdo con las memorias de José María Rangel, se desarrolló el siguiente diálogo:

No estoy dispuesto a subordinarme a usted, porque no obedezco órdenes de nadie, soy miembro del Partido Liberal Mexicano y sólo lucharé por los principios sociales de mi partido -dijo Silva a Madero. Pues quedará usted arrestado - respondió Madero.

No, señor, yo tengo aquí a mis compañeros y daré órdenes para que lo aprehendan a usted, porque usted es el representante del partido burgués.

Mientras tanto, Lázaro Gutiérrez de Lara se había dirigido a las fuerzas de Silva, pronunciando un violento discurso contra la dictadura del general Díaz y pidiendo que los insurrectos reconocieran a Madero como jefe.

Los revolucionarios aceptaron la proposición de Gutiérrez de Lara, y cuando Silva rompió la plática con Madero para pedir a sus compañeros la captura del jefe de la Revolución, pudo descubrir que la 
José InÉs Salazar, una vida en la frontera duRAnte la Revolución...

mayor parte de sus fuerzas lo habían desconocido y así fue como quedó prisionero de los maderistas (Valadés, 2010, p. 48).

La presencia de Madero en territorio nacional, al frente de sus tropas combatientes, fue decisiva para que el magonismo se desintegrara completamente y gran parte de sus simpatizantes se pasaran a un maderismo que, en apariencia, parecía ser capaz de llevar a cabo una revolución social, tal y como el propio Magón lo había preconizado en el Plan del Partido Liberal de 1906.

En ese pequeño poblado, Madero expidió sus primeros documentos autonombrándose presidente provisional, mientras el grupo se dirigió a la zona de Casas Grandes donde esperaba instalar su campamento revolucionario. Así, iniciaron una caravana hacia el suroeste del estado. Eran trescientos hombres y veintiuna carretas cruzando en diagonal de norte a sur el estado de Chihuahua. Fue una travesía difícil: en el mes de febrero, se presentaban todavía temperaturas muy bajas y, con ello, tuvieron que recorrer en veinte días casi trescientos cincuenta kilómetros de estepa, algunos días bajo la nieve.

Animados por las recepciones y la estruendosa recepción de la prensa norteamericana por las primeras acciones militares, continuaron su camino sin muchas previsiones. El 6 de marzo, a las puertas de Casas Grandes, intentaron tomar la ciudad, pero, lastimosamente, con información errónea acerca de las tropas federales que se encontraban defendiéndola, lo que les costó su primera derrota. Se refugiaron en una hacienda cercana y, después de reunirse con Orozco, decidieron internarse al centro de Chihuahua, a la hacienda de Bustillos, propiedad de un tío de Madero. Ahí se reorganizó el ejército insurgente al cual se le unieron personajes como Pancho Villa. Decidieron regresar a la frontera y tomar Ciudad Juárez, un lugar estratégico, porque era el punto de unión del ferrocarril Central Mexicano y los ferrocarriles norteamericanos.

En la ruta de regreso, de Bustillos hacia la frontera, Ciudad Juárez, Madero mandó a los exmagonistas Luis A. García y Lázaro Alanís, a que fueran a Casas Grandes con el fin de proveerse de prendas para la tropa y, en caso de encontrarlas, les indicó que 
se dirigieran a las colonias mormonas para comprarlas. Al llegar, descubrieron que la población de Casas Grandes estaba tomada por las fuerzas de los magonistas Arturo de la Rosa, Porfirio de la Vega y José Inés Salazar, así que improvisaron un mitin junto con ellos. Finalmente, García se dio cuenta de que todo lo que habían comprado fue repartido entre todos, magonistas y maderistas, por cuenta de Lázaro Alanís. Al día siguiente, el 12, llegó Madero a Casas Grandes y cuando le pidió cuentas a García sobre el dinero, este le contó lo que había hecho Alanís, lo que desesperó a Madero, motivo por el cual destituyó a García. Terminado el percance, siguieron su camino a la frontera.

Al considerar que era injusto el regaño de Madero a García y Alanís, en Estación Guzmán, ya muy cerca de Ciudad Juárez, los exmagonistas enviaron una carta a Madero en donde se le decía que, siendo jefes del partido Liberal adheridos al Antirreeleccionista, "no pudiéndonos entender por la mala voluntad que nos ha tenido, por tal razón pedimos a usted nuestra separación del ejército, y si no se nos concede nos la daremos nosotros"; firmaban Lázaro Alanís, Luis A. García, José C. Parra, José Inés Salazar, Leónides Zapata y Tomás Loza. Madero entendió muy bien el papel que Pancho Villa jugaría como contrapeso de los magonistas. En su primer enfrentamiento con ellos, Madero lo mandó llamar y le pidió que los desarmara, lo que hizo sin dificultad y los entregó al líder antirreeleccionista.

Madero los encarceló por rebelión, pero se escaparon y deambularon por el estado, reintegrándose a la lucha armada nuevamente a nombre del magonismo. Aunque la victoria del maderismo produjo el desmembramiento de partido Liberal en Los Ángeles, en Chihuahua la actividad de los magonistas continuó encabezada ahora por Jesús María Rangel, un militante activo del PLM desde 1906. Entre mayo y junio de 1911, junto con José Inés Salazar, atacaron poblaciones fronterizas. Sin embargo, fueron sistemáticamente derrotados por las fuerzas maderistas. Los constantes fracasos determinaron a Salazar a que se retirara con su gente hacia territorio estadounidense, distanciándose de sus compañeros. A partir de esta fecha, se le consideró como desertor. 
José Inés Salazar, una Vida en la frontera durante la ReVolución...

En junio de 1911, los magonistas encabezados por Rangel lograron tomar, a finales de junio, el pueblo de El Sabinal, en el distrito Galeana, sede de la Candelaria Mining Company:

...un niño fue comisionado para que izara una bandera roja con una inscripción que decía "Tierra y Libertad", sobre el asta del edificio de la escuela pública; cientos de proclamas firmadas por la Junta del Partido Liberal fueron repartidas; Rangel llamó al pueblo a un mitin explicando que desde ese momento las tiendas quedaban a disposición del pueblo; los maestros de escuela fueron instruidos para que cobraran, además de sus sueldos, los que percibían las autoridades municipales, y en la plaza fueron quemados los archivos de las oficinas públicas (Valadés, 2010, p. 49). ${ }^{3}$

La columna avanzó hasta el poblado de Ascensión, tomándolo casi sin resistencia. Izaron la bandera roja y proclamaron el derecho de los habitantes para surtirse de todo cuanto necesitaran en las tiendas; el 2 de julio, veinte rurales se enfrentaron al grupo de Rangel, a quien acusaban de haberse robado ochocientos pesos de la tienda del lugar y de llevarse por la fuerza a veinte hombres del pueblo. Posterior a la escaramuza, los magonistas tomaron rumbo con dirección a la frontera (El Paso Morning Times, 3 de julio de 1911, p. 1).

Ahí se les apareció un mensajero de José Inés Salazar, quien les dijo que este había decidido unirse al ejército federal (maderista), pero que jamás lucharía contra ellos por considerarse todavía partidario del ideario magonista, y les pedía a nombre de la guarnición de Ciudad Juárez que se rindieran. Los magonistas se negaron. A los pocos días, perseguidos y derrotados, fueron llevados a Ciudad Juárez para ser juzgados. Con la captura de Rangel, prácticamente se terminó el magonismo armado en Chihuahua.

3 En (1 de julio de 1911) El Paso attorney held up, El Paso Herald, 23, se lee lo siguiente: "los magonistas estaban al mando de un estadounidense llamado Rangel quien a su vez dependía de un Salazar". 


\section{LA REVOLUCIÓN QUE NO FUE}

Madero, victorioso en Ciudad Juárez y reputado como el vencedor de Porfirio Díaz, se encontró desde su llegada a la Ciudad de México, el 7 de junio de 1911, con un mundo convulsionado que no acertaba a rehacerse a posteriori de la renuncia de quien había ocupado la presidencia por más de treinta años. La rápida solución de un presidente provisional en la persona del excanciller Francisco León de la Barra no satisfizo a nadie. Muy pronto se enfrentó a dos movimientos armados: el primero fue en el sur, en Morelos, liderado por Emiliano Zapata, apenas realizada la toma de posesión; el otro, en Chihuahua, con personajes como José Inés Salazar.

Allí se propagaban las decepciones. Ocurrido el triunfo maderista, que muchos chihuahuenses sintieron como propio debido a su participación en la lucha armada, estallaron movimientos por reivindicaciones laborales, tanto en las empresas agrícolas y mineras como en las urbanas. A partir de junio de 1911 fueron muy frecuentes las manifestaciones de trabajadores por las calles de la ciudad de Chihuahua en demanda de mejoras salariales y de condiciones de trabajo. Los inconformes habían aprendido a hablar en público. Tenían ahora la confianza de haber ganado, aunque solo fuera militarmente una lucha importante. Ahora no sería fácil hacerlos callar.

En el mineral y hacienda de Corralitos, y en general en la zona de Casas Grandes, la situación para los mexicanos empeoró con la victoria maderista:

...los trabajadores de las minas de San Pedro han sido desalojados de sus hogares por protestar contra las injusticias de que los mexicanos son víctimas de los gringos malévolos y perniciosos. La misma compañía ha llevado carros a los humildes hogares para sacar a los indefensos y laboriosos trabajadores por la fuerza y llevarlos a los caminos donde los han dejado a merced de la inclemencia de la temperatura... Los mismos gringos declaran que ellos son absolutos y que no habrá autoridad mexicana que les pueda impedir las degradadas intenciones. Estos pueblos están indignados y no será remoto 
José Inés Salazar, una vida en la frontera duRAnte la ReVoludión...

que se remonten a las sierras y por la decepción, cometan toda clase de tropelías (El Siglo XX, 16 de noviembre de 1911, p. 2).

Por las calles circulaba un manifiesto firmado por José Inés Salazar, en el que pedía a los chihuahuenses, "los primeros en levantarse contra la tiranía de Díaz", que no aceptaran ahora la nueva tiranía de los Madero, apoyada por los antiguos porfiristas, y la imposición arbitraria de personajes como Pino Suárez. La revolución, añadía, no había sido hecha para cambiar a unos tiranos por otros, sino para remediar los males nacionales, con el objetivo de gozar de una congruente impartición de justicia, una tasa justa de impuestos, destruyendo el favoritismo que hace recaer sobre los más pobres un peso insoportable, y una ecuánime división de la propiedad territorial. Demandaba de inmediato la nulidad de las recientes elecciones presidenciales, la disolución del Congreso de la Unión y elevar a la presidencia a Emilio Vázquez Gómez (El Paso Morning Times, 1 de febrero de 1912, p. 1).

Salazar, junto con Demetrio Ponce y Emilio Campa -los magonistas a los que Villa había sometido en Estación Guzmán en 1911 - y el recién instalado presidente municipal, Enrique Portillo, se rebelaron contra el gobierno federal. Ponce había sido funcionario durante el porfirismo, periodo en el que intentó impedir algunos abusos. Acabó por pasarse al magonismo en 1906-1907; Campa era nativo del distrito de Galeana cerca de Casas Grandes, hijo de un rico hacendado. A los dieciocho años fue a estudiar a Misuri, donde se graduó de médico en 1911 a los veinticinco años y se unió a Orozco; Portillo, también de la región de Casas Grandes, se integró al magonismo desde 1906 y tenía estudios en la academia Juárez, la excelente casa de estudios patrocinada por los mormones.

Los tres emitieron primero un manifiesto publicado en El Paso Herald, en el que decían que se levantaban en armas "contra el despótico presidente Madero... de manera ordenada y disciplinada”, aunque advertían haber tenido que volar trenes y puentes, pues Madero no solo no había cumplido con el Plan de San Luis Potosí, sino que, además, dilapidaba el tesoro de la Nación, mientras las viudas y los huérfanos de 
revolucionarios estaban en la más completa miseria. Hacían mención de llevar a la presidencia a Emilio Vázquez Gómez. Pedían, además, interceder ante el gobierno norteamericano para que no permitiera el paso de tropas mexicanas por su territorio (El Paso Herald, 15 de febrero de 1912, p. 1). En otro manifiesto, firmado en Casas Grandes, nombraban a Orozco jefe del ejército libertador, al mismo tiempo que reivindicaban la bandera del partido Liberal Mexicano con el lema publicitado en México por los magonistas: "Tierra y Libertad".

Mientras tanto, los diarios de El Paso denunciaban que entre doscientos cincuenta y trescientos hombres, bajo el mando de José Inés Salazar, recorrían la región atacando las colonias mormonas, como la de Dublán, en donde mataron seis de las más finas reses, terminaron con buena parte de su establo lechero y que era evidente la intención fundamentada en el simple gusto de destruir, puesto que muchas de las víctimas consistían en becerros que fueron regados por los campos; además, asaltaron la tienda La Unión Mercantil, propiedad de mormones (El Paso Morning Times, 10 de febrero de 1912, p. 1; 26 de febrero de 1912, p. 1).

El 23 de febrero de 1912, se evidenció la movilización de los casagrandinos hacia Ciudad Juárez, encabezados por Salazar, y este, el 26 del mismo mes, pidió la rendición del poblado fronterizo. A los cuatro días, a las siete de la mañana, los setecientos rebeldes asaltaron Ciudad Juárez y, seguidamente de haber intercambiado algunos disparos, los defensores se rindieron sin mucha resistencia. Salazar y Campa acuartelaron a su gente. Dos días más tarde, llegó a la ciudad otro de los rebeldes, muy popular en la lucha de 1910 y 1911, Antonio Rojas, con otros setecientos hombres, con lo cual la guarnición de Ciudad Juárez llegó a casi dos mil, contando con los simpatizantes de la misma localidad (Stimson, 1912, BI3). A la mañana siguiente, las autoridades norteamericanas reabrieron la aduana de El Paso. Ese día, José Inés Salazar nombró a

4 El documento se encuentra reproducido en Amaya (2010), Madero y los auténticos revolucionarios de 1910, pp. 370-371; sobre el lema de “Tierra y Libertad”, véase: Beltrán Denigra, J. (2008), Tierra y libertad. La opinión sobre la Revolución mexicana (19111917) en la prensa anarquista española. Espiral. Estudios sobre Ciencia y Sociedad, XIV(41). 
José InÉs SAlazar, una Vida en la frontera duRAnte la ReVolución...

Demetrio Ponce como nuevo presidente municipal. En una entrevista, tras ser nombrado alcalde de Ciudad Juárez, dijo que:

No tenemos dudas de que capturaremos la ciudad de Chihuahua muy pronto... Pascual Orozco será entonces comandante en Jefe de las fuerzas Liberales y procederemos a capturar la capital federal para llamar a nuevas elecciones. Por lo que respecta a Pancho Villa, le diré que no contamos para nada con él. Cuando le pongamos las manos encima lo colgaremos y libraremos de él al país. No permitiremos que hombres como él se afilien a nuestro partido. Por lo que respecta a Madero, es un muñeco en manos de su hermano Gustavo y a ambos les haremos pagar por las aflicciones que han pasado los pueblos de México. Madero está ahora pagando por el desarme que hizo de los liberales en Guzmán y sufrirá más todavía (El Paso Morning Times, 29 de febrero de 1912, p. 1).

El 29 de febrero llegaron a Ciudad Juárez, David de la Fuente y Paulino Martínez, para iniciar formalmente la campaña de otro antimaderista: Emilio Vázquez Gómez, con un mitin frente a la Presidencia Municipal donde José Inés Salazar pronunció un discurso a favor de este. Se instaló una junta vazquista sostenida militarmente por las fuerzas que provenían de Casas Grandes y se levantó el acta donde se asentaba que:

Se acordó invitar de algún modo al Gral. Pascual Orozco para que tome el mando militar de la Revolución y... desde el momento en que el licenciado Vázquez Gómez pase al territorio nacional será considerado con el carácter de presidente de Estados Unidos Mexicanos, con todas las facultades y consideraciones necesarias para llevar al triunfo los ideales de la Revolución (Almada, 1964, p. 300).

El 2 de marzo, Orozco finalmente renunció como jefe del ejército maderista en Chihuahua y se unió a los rebeldes encabezados por Salazar, a quienes envió un telegrama en el que les comentaba el suceso y les pedía que se reunieran con él en la ciudad de Chihuahua, "siempre que se sometiesen y coadyuvasen a guardar 
el orden" (El Correo, 4-5 de marzo de 1912, p. 1; El Paso Herald, 4 de marzo de 1912, p. 1).

\section{SALAZAR: EL MEJOR GENERAL DE OROZCO}

En el lugar conocido como El Mimbre, aledaño a los patios de carga del ferrocarril Central, acordaron reunirse para proclamar jefe supremo a Pascual Orozco. En medio de todas las fuerzas militares congregadas, juraron lealtad e, incluso, sacrificar su vida por la causa: “iprotestáis por vuestro honor y por vuestra vida, y por el honor y la vida de vuestros hijos, luchar por el Plan de San Luis Potosí, reformado en Tacubaya y de conformidad con la parte relativa al Plan de Ayala?", a lo que contestaron afirmativamente. Expresaron que el lema sería “Tierra y Justicia” y firmaron ante notario público su adhesión a la causa. "Sobre la mesa flotaban dos banderas, una era la nacional y la otra una bandera roja”, escribió el corresponsal de El Paso Morning Times, y los rebeldes llevaban una cinta roja en el brazo con el lema seleccionado, por lo que recibieron el nombre de "Colorados" (El Paso Morning Times, 7 de marzo de 1912, p. 1; El Correo, 6-7 de marzo de 1912, p. 1; Crónica de la revolución, 1912, p. 68; Terrazas, 1985, pp. 55-56).

Por su parte, José Inés Salazar ya no quería saber nada de Ricardo Flores Magón y del antiguo PLM. Durante los corrillos políticos, se ironizaba que no había nada que lo hiciera enojar más que recordarle su pasado magonista. En una entrevista, otro de los generales, Campa, declaró que "puede usted escribir tan enfáticamente como quiera que nosotros no somos magonistas y que no tenemos nada que ver con él ni con sus seguidores confesos" y agregó que: "Magón es un anarquista y nosotros no somos anarquistas" (El Paso Herald, 6 de marzo de 1912, p. 11). Por otra parte, el grito de Salazar era: “ipoco tiempo, California!”, o sea, un llamado a la recuperación de los territorios perdidos en 1848 que tanto inspiraba a los habitantes de la zona de Casas Grandes.

Salazar inició la ofensiva orozquista hacia el sur por la vía del ferrocarril Central. Su primera gran victoria fue el 12 de marzo cuando tomó la población de Camargo y, más adelante, en el poblado de Boquilla de Conchos hizo huir a Villa, quien salió a re- 
fugiarse a Parral. Las tropas federales, ahora maderistas, sufrieron un percance tras otro ante el avance de los orozquistas.

En la Ciudad de México, Madero organizó un ejército al mando del general José González Salas y salieron a combatir al norte. La campaña de González Salas fue una de las más desastrosas que se recuerde y culminó con su derrota y consecuente suicidio cerca de la estación Rellano en los linderos de los estados de Coahuila y Chihuahua. El triunfo rebelde pareció rotundo cuando supieron que González Salas se había suicidado y Orozco, envalentonado por la victoria, anunció que próximamente entraría a la Ciudad de México con una fuerza de ocho mil hombres (El País, 7 de marzo de 1912, p. 1; Resendi, 1912, p. 95).

El Plan Orozquista se dio a conocer después de Rellano como parte de la euforia de las victorias militares. Fue fechado el 25 de marzo y se conoció como el Pacto de la Empacadora, ya que fue firmado en un paraje con ese nombre. Allí se decía que era una síntesis del Plan de San Luis y el de Ayala, pronunciado por Zapata. Como todos los anteriores, se acusaba a Madero de ladrón, traidor a la revolución, y se desconocía a su gobierno.

El Plan fue el más completo que existió en la revolución sobre las demandas populares, ya que reunía a los exmagonistas, exmaderistas, exreyistas, vazquistas, zapatistas y, quizá, algunos más. En él se pedía la supresión de las tiendas de raya, el pago en efectivo a los trabajadores, la jornada máxima de diez horas, una reforma agraria en la que establecían que a quien hubiera residido diez años en un predio, se le daría el título de propiedad —en otras palabras, a los medieros-, la devolución de tierras arrebatadas por los hacendados y que las tierras baldías y nacionalizadas serían repartidas; los terrenos que las grandes haciendas no utilizaran, serían expropiados previo avalúo y los hacendados recibirían el 4 $\%$ de interés anual hasta que se les pagara completamente; esto se haría porque los nuevos propietarios los pagarían en diez años y con módico interés. Además, el Plan pedía la nacionalización completa e inmediata de los ferrocarriles y el uso exclusivo de personal mexicano en sus operaciones. 
Ante la victoria de Rellano, José Inés Salazar, con sus ochocientos hombres, tomaron la ciudad de Parral el día 4 por la noche casi sin resistencia de Villa, quien la defendía con trescientos partidarios que se retiraron al sur (El Paso Morning Times, 6 de abril de 1912, p. 1). La entrada de los orozquistas a Parral fue desordenada y violenta. Pronto, el propio Salazar tuvo que reconocer que había perdido el control de sus hombres, puesto que saquearon la ciudad sin reconocer ninguna autoridad (Katz, 2018, pp. 193-194).

Como un incidente memorable en la toma de Parral, fue fusilado Tomas Fountain, de nacionalidad estadounidense. Su familia era de Nuevo México: su padre fue el político republicano más influyente de la región de Las Cruces, Albert Fountain, hasta que desapareció misteriosamente cuando viajaba con el objetivo de presentar pruebas criminales contra su más encarnizado enemigo, el demócrata Albert B. Fall, quien ha sido mencionado insistentemente como el autor intelectual de la desaparición física de Fountain. El hijo de este, Tomás, había jurado vengar la muerte de su padre, y había razones para temer que lo hubiera hecho, pues era un bandido incorregible. Al parecer llegó a Parral en 1910 y al año siguiente se había sumado al maderismo como soldado a sueldo a las órdenes de Tomás Urbina. Licenciado, se dedicó a robar ganado en la zona de Janos y Ascensión, y a llevarlo a Nuevo México vía Columbus. Regresó a Parral con la encomienda de asesinar a un estadounidense de apellido Gillet. No obstante, a cambio de eso, lo extorsionó y le reveló el nombre de sus patrones. En eso se encontró con un amigo, Pancho Villa, y aceptó quedarse a defender Parral (El Imparcial, 26 de abril de 2012, p. 10). Fountain había colocado su ametralladora en el cerro De la Cruz, pero quedó inmovilizada al recibir alrededor de cien disparos. Acabó por esconderse en una farmacia de la ciudad junto con su arma. Descubierto, fue llevado ante José Inés Salazar y fusilado al día siguiente (El Paso Morning Times, 11 de abril de 1912, p. 2; El Diario, 11 de abril de 1912, p. 2). Esto provocó una enorme protesta por parte de los norteamericanos, que, junto con lo de Casas Grandes, aumentó la impopularidad de Salazar en la prensa de Texas y Nuevo México. 
José Inés Salazar, una vida en la frontera durante la ReVolución...

Cuando se conoció la derrota de Rellano y la amenaza de los orozquistas de llegar hasta la Ciudad de México, Madero organizó otro ejército, ahora al mando de uno de los generales más conocidos dentro de las filas federales por su capacidad en campaña: Victoriano Huerta Márquez.

Huerta salió de la Ciudad de México el 10 de abril con uno de los ejércitos mejor pertrechados de los que se tenga memoria: tenía cañones de grueso calibre de sobra, un sinfín de ametralladoras y abundante parque, así como ambulancias, víveres, médicos y todo lo necesario para una campaña moderna, lo que incluía dos aviones tipo Blériot recién comprados a Francia, "completamente provistos de todo el material necesario para el servicio en tiempo de guerra”. Además, algunos agregados militares estadounidenses en calidad de observadores (Boletín Militar de la División del Norte, 7 septiembre de 1912, n. 5, 7). ${ }^{5}$

Madero fue a la estación de trenes a despedirlos y pidió a todos sus simpatizantes el apoyo para la campaña. Villa reapareció tras su salida de Parral y se reunió con Huerta en Mapimí, Durango, el 19 de abril. En total, Huerta logró reunir en Torreón una columna de diez mil hombres entre tropa de línea e irregulares.

Fue en Conejos, cerca de Rellano, el 12 y 13 de mayo, donde entablaron el combate formal. Huerta tenía diez mil hombres, cañones de grueso calibre, abundancia de parque y equipo médico, además de los grupos de irregulares de Francisco Villa. ${ }^{6}$ Era un día muy caluroso y estaban a la mitad del desierto. Las fuerzas al mando de José Inés Salazar constaban de alrededor de cinco mil hombres organizados, para resistir un combate defensivo por medio de unas trincheras y cercos de piedra. El combate se desplegó en un área de diez kilómetros de las ocho de la mañana a las seis de la tarde. La sorpresa fue la magistral utilización de la artillería a cargo de Guillermo Rubio Navarrete, quien hizo estra-

5 Boletín Militar de la División del Norte, 7 de septiembre de 1912, n. 5, 7. La presencia de los agregados militares puede confirmarse en "Cómo juzga a nuestro ejército el agregado militar de la embajada de los Estados Unidos..." (El Diario, 19 de julio de 1912, p. 5).

6 Caraveo dice que tenían entre cuatro mil y cinco mil hombres; y cita equivocadamente la fecha del 23 de mayo para el combate de Conejos (1992, p. 71). 
gos desde sus primeros disparos que alcanzaban al enemigo a tres mil quinientos metros de distancia. Entre su artillería estaba el famoso cañón "El Niño"; posteriormente, les lanzó la caballería de Villa y, enseguida, la infantería con los irregulares al frente. La presencia de Villa fue muy importante por dos razones: la primera, es que sus irregulares eran la punta de lanza del ejército federal que permitía descubrir las posiciones enemigas; posteriormente, Rubio Navarrete, con sus cañones, bombardeaba sin misericordia, además de que barría las laderas con las ametralladoras más modernas de ese momento, las Rexer, capaces de lanzar cuatrocientos cincuenta disparos por minuto, ${ }^{7}$ y con cañones de campaña que lanzaban cien bombas en treinta segundos.

Los orozquistas sufrieron el embargo de armas norteamericanas con una severidad que nunca antes había sucedido. Además, se prohibió la compra de ganado chihuahuense, el envío de giros telegráficos para impedir que recibieran dólares e, incluso, se vedó el paso de alimentos entre Ciudad Juárez y El Paso (maíz, frijol, etcétera), y, por si fuera poco, la policía norteamericana, junto con empleados del Consulado mexicano, catearon domicilios en El Paso en busca de orozquistas para encarcelarlos (Pierson, 1975, pp. 54-55).

Los rebeldes debieron abandonar sus posiciones, pues su deficiente artillería, que consistía sobre todo en tubos lanzagranadas hechos en talleres artesanales a partir de ejes de carros de ferrocarril perforados, era incapaz de competir con los abastecimientos federales, lo que significó que fueran diezmados por las granadas enemigas. A doce horas de haber iniciado, el combate había terminado. Los sobrevivientes emprendieron la retirada y dejaron cuatrocientos muertos; doscientos heridos; ciento siete carros de ferrocarril, entre ellos, treinta y seis furgones repletos de provisiones de boca y de las preciosas municiones; tres locomotoras y otros implementos de campaña (Boletín Militar de la División del Norte, 21 de septiembre de 1912, pp. 2-4; Sánchez Lamego, 1976, p. 73).

7 El fusil-ametralladora norteamericano Rexer era una copia de la ametralladora Madsen de Dinamarca calibre 7x57, que permitía cuatrocientos cincuenta disparos por minuto, un arma sorprendente para su época. 
Huerta continuó su marcha unos noventa kilómetros hacia el norte, hacia Rellano. Iba cumpliendo paso a paso sus predicciones sobre la guerra. Así, el miércoles 22 de mayo comenzó la segunda batalla de Rellano; seis mil rebeldes orozquistas se fortificaron en un tramo de siete kilómetros en las faldas del monte Rellano, mientras que cinco mil federales avanzaron comandados por Huerta y con Villa al frente. El fuego de la artillería federal fue certero. Salazar y el propio Orozco hacían esfuerzos inauditos para detener a sus soldados, que, desmoralizados, emprendían la huida desordenadamente al no poder defenderse, debido a la gran distancia que disparaban los cañones federales. Durante la noche, el bombardeo siguió mientras la infantería federal descansaba; al amanecer, los orozquistas permanecían en sus trincheras sin dormir. Por la mañana, las fuerzas de Villa cercaron las posiciones enemigas y el combate fue casi cuerpo a cuerpo.

El combate había durado veintidós horas y durante él, los federales dispararon tres mil cañonazos y un millón de tiros de fusil. Las pérdidas federales fueron relativamente insignificantes en comparación con las de los rebeldes, pues estos tuvieron poco más de cien bajas, mientras que los rebeldes seiscientas. La diferencia de bajas se debió a la artillería federal, porque mientras disparaban sus proyectiles a siete kilómetros de distancia, los rebeldes no alcanzaban más de mil doscientos metros. Se inició el repliegue orozquista en varios grupos: unos se internaron en el desierto donde murieron por la desesperación, el calor y la sed (Caraveo, 1992, p. 74).

Las tropas quedaron diseminadas por todo Chihuahua y José Inés Salazar, se estableció en la zona de Casas Grandes. Los mormones habían conocido las advertencias de expulsarlos del país y decidieron defenderse, así que enviaron desde abril de 1912 a uno de ellos para que comprara una buena dotación de armas de alto poder, máuseres, y las enviara a las colonias de Chihuahua. El comisionado fue Orson Patt Brown, quien compró doscientos cincuenta rifles y diez mil cartuchos, y logró impresionar al presidente estadounidense con historias de horror con respecto a lo que sufrían los mormones. 
Cuando Salazar llegó, enterado de la compra, ordenó a las colonias mormonas que entregaran todas sus armas y parque a los rebeldes, a cambio de no molestarlos en sus propiedades. Los mormones cumplieron parcialmente la orden, entregaron unas antiguas y de bajo calibre y guardaron celosamente las nuevas. Salazar no cayó en el engaño y aumentó la presión sobre ellos. Ante la disyuntiva de entregar las armas o pelear, decidieron entregarlas y comenzaron a su vez a emigrar a la frontera en busca de seguridad. El cónsul Edwards intervino alegando la neutralidad de los mormones en el conflicto, pero fue inútil: Salazar insistía en que no eran neutrales, sino "dos caras" y que necesitaba urgentemente las armas.

En la zona de Galeana, y en especial en las colonias mormonas, la situación se tornó aún más difícil. Las tropas federales habían saqueado parte de los campos. Tras de ellos, llegaron las partidas de orozquistas huyendo hacia Sonora; pasado el tiempo, regresaban los federales persiguiéndolos y así en adelante. El éxodo masivo de los mormones sucedió a partir del 28 y 29 de julio, cuando mujeres y niños salieron de las colonias Juárez y Dublán en los trenes del noroeste; el 7 de agosto se marcharon otros grupos hacia la frontera en carretas, buscando refugio en Hachita, Nuevo México, donde el gobierno estadounidense les instaló quinientas tiendas de campaña, así como en El Paso, donde se instalaron ochenta lugares para mil quinientas personas y se les destinaron veinte mil dólares. Existen muchas fotos en las que se les muestra en corrales, depósitos de ferrocarril, madererías y otros lugares semejantes. Para entonces, cinco mil mormones habían abandonado la zona. Entre julio y diciembre, los mormones conocerían una época de sobresaltos, éxodo y asilo en El Paso (Hardy, \& Seymour, 1997, pp. 305-306; Smith, 2000, pp. 66-68; Grant, 1991).

Con una fuerza cercana a los dos mil hombres, Salazar tomó, como otras veces, el aserradero de Pearson, entre Madera y Nuevo Casas Grandes, donde pronunció otro de sus discursos incendiarios contra los estadounidenses y despojó de rifles y cartuchos a los guardias de la empresa. Dijo que la tragedia de México era la de un pueblo que trabajaba como esclavo y vivía en una pocilga, mientras el jefe extranjero vivía como rey; la intervención militar 
estadounidense, agregó, sería bienvenida, porque haría caer la máscara con que disfraza hoy su intervencionismo apoyando a Madero (El Paso Herald, 31 de julio de 1912, p. 1).

Los norteamericanos se quejaban de que los orozquistas habían comenzado las depredaciones a partir de la toma de Huerta en la ciudad de Chihuahua y la desbandada de los orozquistas, y que sus propiedades eran las únicas afectadas, ya que los rebeldes respetaban las de los mexicanos, ingleses y alemanes (El Paso Morning Times, 8 de septiembre de 1912, p. 1). El Paso Morning Times, que había permanecido contra la entrada de las tropas estadounidenses en México, comparaba a los orozquistas con "los antiguos levantamientos apaches", sobre todo en cuanto a los ataques que asediaron a las colonias mormonas, y clamaba en sus editoriales — sin decirlo explícitamente- por una intervención estadounidense en el norte de México (El Paso Morning Times, 2 de agosto de 1912, p. 6; El Paso Herald, 19 de junio de 1912, página editorial).

A inicios de diciembre de 1912, la guerrilla de Salazar continuó asolando la zona fronteriza y la de Casas Grandes y sus alrededores. Los once mil soldados federales en Chihuahua parecían impotentes y cada vez más debilitados. Poco a poco las páginas de los periódicos locales fueron llenándose de notas sobre puentes quemados y pequeños pueblos asaltados. Lo peor fue el 19 de diciembre, en el momento en que se anunció que, rehechas las tropas de Salazar, estaban dispuestas a tomar Ciudad Juárez. De hecho, estaban a cuarenta kilómetros de ella, con tres mil hombres dispuestos a tomarla, pese a los mil soldados federales que la defendían (El Paso Morning Times, 19 de diciembre de 1912, p. 1). El 23 de diciembre de 1912 tomaron Ascensión, a unos doscientos kilómetros al oriente de Ciudad Juárez sobre la línea del ferrocarril con dirección a Casas Grandes. Incendiaron la Presidencia Municipal junto con los archivos del pueblo, con lo que el edil tuvo que huir. 
Madero destituyó a Huerta por los rumores de que preparaba un golpe de Estado, y nombró al general Rábago como encargado de las tropas, ${ }^{8}$ a quien le escribió:

Parece que la situación puede complicarse si no se termina pronto la pacificación, pues numerosos americanos que tienen sus propiedades por la región de Casas Grandes, Palomas, etc., se quejan amargamente del estado de cosas reinante allí. Aseguran que Salazar transita por allí casi sin que lo molesten para nada, que seguido va a El Sabinal y que está en comunicación telegráfica con El Paso, Texas, y les extraña que la persecución no sea más activa. Le aseguro General, que está causando a toda la nación seria inquietud la prolongación de esa guerra, y le reitero las esperanzas que todos tenemos puestos en usted (15 de enero de 1913, rollo 11).

A fines de 1912, la situación en Ciudad Juárez era semejante, en cierto modo, a la de abril de 1911: la ciudad estaba rodeada por los rebeldes, el ejército federal se mantenía impasible y se negaba a perseguirlos. La pregunta que se hacían los habitantes de la ciudad era: ¿tiene Madero de su lado al ejército? Pronto encontrarían la respuesta.

En enero de 1913, en Chihuahua había once mil soldados federales, y Salazar era imbatible, además de tener amenazado a todo el estado. Como podía verse, en el poblado de Guadalupe -aquel lugar fronterizo donde Madero apresó al magonista Silva e inició su marcha hacia Casas Grandes en febrero de 1911 - vivían ahora con toda tranquilidad José Inés Salazar y muchos más sin que nadie los molestara. ${ }^{9}$ El periodista Norman Walker reportaba que era evidente que Orozco ya no era el jefe de la rebelión, sino Salazar, pues aquel no tomaba ninguna iniciativa y era desconocido su

8 Tanto el gobernador de Chihuahua, Abraham González, como Juan Sánchez Azcona y el cónsul mexicano en El Paso, Enrique Llorente, advirtieron a Madero sobre la conducta sospechosa de Huerta, pero los hermanos Madero, Gustavo y Emilio lo defendieron siempre.

9 Un reportaje sobre la tranquilidad en la que vivían y recibían a sus visitas los jefes rebeldes: Rojas says he is not so bad man, El Paso Herald, 28 de febrero de 1912, página editorial. 
paradero (El Paso Herald, 27 de enero de 1913, p. 1). Se supo que se hallaba escondido en una zona de minas abandonadas cerca de Marfa, Texas, abatido por las reumas provocadas por pernoctar al aire libre.

El 20 de febrero se anunció en la frontera la renuncia de Madero. Un soldado desconocido, ebrio, gritó en una calle céntrica de Ciudad Juárez: “¡Viva Madero!”, e inmediatamente un guardián del orden trató de arrestarlo. El soldado se resistió, trató de sacar su arma para defenderse, pero fue desarmado por un grupo de policías que se habían acercado y fue conducido a la prisión. Su suerte permanece desconocida (El Paso Morning Times, 21 de febrero de 1913, p. 1).

\section{BAJO LA ALIANZA CON EL HUERTISMO}

Rodolfo Reyes, hijo de Bernardo Reyes -fallecido durante la Decena Trágica- y secretario de Justicia en el gabinete de Huerta a partir del 18 de febrero, telegrafió inmediatamente a Ciudad Juárez para que localizaran a José Inés Salazar, para que este dejara de combatir y se uniera al esfuerzo de pacificación. El 8 de marzo los diarios locales informaron de la llegada de Salazar a El Paso y su actitud fue ambigua durante los primeros días. En algunas entrevistas no dejó de mencionar que en los últimos meses era él quien había llevado sobre sus hombros todo el peso de la lucha armada. Finalmente dijo que su alianza con Huerta había sido porque "era el único en esos momentos que podía lograr la paz" (El Paso del Norte, 24 de marzo de 1913, p. 3; El Paso Herald, 5 de marzo de 1913, p. 1; 22 de enero de 1915, p. 1). Orozco permanecía escondido en algún lugar de la frontera.

Mientras tanto, el primer levantamiento contra Huerta sucedió en los alrededores de Parral a cargo de Manuel Chao y posteriormente Villa entró a Chihuahua a organizar lo que con el tiempo se conocería como la División del Norte.

José Inés Salazar, con setecientos cincuenta hombres, fue nombrado por las autoridades huertistas como jefe militar en Nuevo Casas Grandes y en una ocasión se dirigió, como tantas veces, 
a El Paso. Solo que esta vez, el 14 de junio, no fue tan bien recibido como en otras ocasiones, puesto que trató de alojarse en un gran hotel, donde un grupo de los antiguos miembros de la legión de extranjeros de Madero decidió que ahora pagaría por los abusos que él había cometido en México contra los norteamericanos.

El plan era arribar al hotel, uno por uno, y sentarse a esperarlo tranquilamente en los sillones del lobby. Se simularía una pelea y en medio de la trifulca, se eliminaría a Salazar. Pero el jefe de policía de El Paso se enteró, llegó al hotel, tomó preso a Salazar y se lo llevó a la cárcel antes de que los legionarios tuvieran tiempo de ejecutar su plan. Salió inmediatamente bajo una fianza de mil dólares (Bush, 1939, p. 226).

Las condiciones de los antiguos orozquistas, y ahora huertistas, eran en extremo difíciles, ya que carecían de armas, municiones y todo tipo de apoyo. Tenían en su contra todo el aparato propagandista norteamericano y el bloqueo económico. Muchos de ellos, al advertir que se repetían las circunstancias de 1912, se desmoralizaron y comenzaron a desertar.

A principios de noviembre de 1913, posterior a la toma de Torreón, Villa estaba a las puertas de la ciudad de Chihuahua, defendida por las fuerzas federales y sus aliados, los antiguos orozquistas. No pudo tomarla, y aprovechando el paso de un tren de carbón, organizó una estratagema para subir a sus tropas y, de manera sorpresiva, tomar Ciudad Juárez.

Para recuperar la ciudad fronteriza, el general federal Salvador R. Mercado embarcó a todas sus tropas en trenes rumbo al norte llevando a Salazar al frente de los irregulares. Los federales se enfrentaron con el enemigo villista en un punto conocido como Tierra Blanca, a unos treinta kilómetros antes de llegar a la ciudad. Allí, los federales huertistas y orozquistas sufrieron una enorme derrota y Villa se decidió a tomar Chihuahua. El general huertista Salvador Mercado contra toda lógica, en vez de dirigirse a Torreón, decidió huir hacia Ojinaga (Mercado, [s.p.], [s.f.]). La razón no se conoce con precisión. En su libro evade aclaraciones. Este general era: 
José Inés Salazar, una vida en la frontera duRAnte la ReVoludión...

...un hombre muy rico, en su mano derecha ostentaba un diamante de tres o cuatro quilates, una cadena de oro en el cuello, lentes con arillos de oro, otra cadena de oro a su reloj y adherido, un triángulo símbolo de la masonería del rito escocés, de la que es maestro en grado 33 (El Paso Herald, 20 de enero de 1914, p. 2).

Las fuerzas que salieron en tren hacia Ojinaga constaron de dos mil quinientos elementos a las órdenes de Pascual Orozco y unos tres mil regulares a las del general Mercado. En aquellos días, solo se había construido un tercio de la vía férrea de la distancia entre Chihuahua y Ojinaga a cincuenta y cinco millas, al oriente del territorio chihuahuense, donde Mercado decidió quemar los once trenes con todo lo que no pudo llevar, incluyendo alrededor de ciento cincuenta mil cartuchos. Tuvieron que recorrer a pie, durante siete días, las cien millas restantes y padecieron el frío de enero en el desierto, muy por debajo del punto de congelamiento. La huida a Ojinaga no tuvo justificación militar (Meyer, 1984, pp. 133-134); quizá lo único que buscaba Mercado era huir a Estados Unidos con su fortuna.

Villa los alcanzó en Ojinaga y la derrota de Mercado fue completa el 1 de enero de 1914. A partir de entonces, muchos federales y orozquistas huyeron por territorio norteamericano; algunos fueron recluidos en campos de internamiento y otros, se dispersaron por todo Texas. El 12 de enero José Inés Salazar fue capturado en la estación de Sanderson, Texas, del Southern Pacific, y enviado a Nuevo México donde tenía una cuenta pendiente cuando se escapó del arresto domiciliario. Luego de permanecer en Fort Wingate, Nuevo México, fue llevado a una corte federal en Albuquerque y recluido en la cárcel, pero dos enmascarados dominaron a los guardias de la misma y lo sacaron de su celda en el segundo piso del edificio. La fuga estaba bien planeada (pp. 144-145). Posteriormente, con sus sesenta y dos hombres, asaltó por enésima vez el rancho Corralitos. A principios de 1915, se conoció el Plan de San Diego, firmado, entre otros, por Salazar y su antiguo amigo, Campa, que pretendía crear una república en los antiguos territorios de Texas, Arizona y California (Gerlach, 1968). 
Victoriano Huerta, después de su salida de México en junio de 1914, organizó desde Europa una alianza con algunos mexicanos, a quienes acudió con el fin de solicitar apoyo para regresar y organizar un movimiento armado. ${ }^{10}$ Huerta logró obtener el apoyo de Pascual Orozco y este, a su vez, convenció a Salazar para secundarlo en esta nueva aventura. Tanto Huerta como Orozco y Salazar tenían profundos sentimientos antinorteamericanos, por lo que no fue difícil unirlos. La fecha para iniciar el movimiento fue el 28 de junio de 1915, mas, un día antes, al llegar Huerta a la estación Newman en la frontera con México, donde Orozco lo estaba esperando, las autoridades norteamericanas arrestaron a ambos, con lo cual el plan fracasó.

Salazar, que no fue detenido, se regresó al distrito de Galeana, y de enero a junio de 1915 mantuvo su guerra de guerrillas en ese distrito, cortando vías de comunicaciones y hostigando a los villistas.

\section{CONTRA Y CON VILLA}

Para 1916, Villa intentaba recuperarse en Chihuahua del fracaso del gobierno de la Convención, de sus derrotas en el Bajío el año anterior, de la pérdida de hombres tan cercanos a él como Felipe Ángeles y Rodolfo Fierro, y también de la hostilidad norteamericana derivada de lo ocurrido en Columbus y la persecución encabezada por el general Pershing para apresarlo. Salazar, entonces, se internó a México y pidió a Carranza que le permitiera luchar contra la intervención norteamericana en Veracruz, pero, en cambio, fue apresado y condenado a fusilamiento. Fue entonces cuando Villa lo liberó.

A los pocos días de su liberación, Salazar se separó de Villa para recorrer la región de Casas Grandes y tratar de reclutar volun-

10 Al parecer, hubo acercamientos al respecto con Alemania. Véase: Meyer, M. C. (1960), The Mexican-German Conspiracy of 1915, The Americas, 23(1), 76-89. Otros detalles pueden encontrarse en el capítulo The Revolt of the Exiles, en Meyer, M. C. (1972), Huerta: A Political Portrait, Nebraska, University of Nebraska Press; Huerta in Exile, en Rausch, G. J. (1960), Victoriano Huerta: A Political Biography (tesis de doctorado), Illinois, University of Illinois. 
José Inés Salazar, una vida en la frontera duRAnte La ReVolución...

tarios para continuar la lucha ahora desde el villismo; sin embargo, ya no fue posible. A su regreso, platicó con Villa, "de una manera en extremo cordial y un poco chusca”, escribió Jaurrieta (1997), pues el exorozquista narró que todos sus intentos fracasaron y que únicamente regresó de su expedición con la escolta que le habían proporcionado. El general Villa intentó animarlo diciéndole:

no se apure mi general, es cierto que le fue del tormento, pero así es la vida. ¡Míreme a mí! Me dejó con poquitos y como usted ve, es hora que están averiguando con [Jacinto B.] Treviño cerca de tres mil muchachitos (p. 64).

El 27 de noviembre de 1916, Villa tomó nuevamente Chihuahua. Para entonces, el general Pershing andaba a la caza del Centauro durmiendo a la intemperie, mientras aquel dormía en el $\mathrm{Pa}$ lacio de Gobierno. Cuando supo que el general Francisco Murguía había sido comisionado por Carranza para recuperar la ciudad, mandó a Salazar con unos diez mil hombres a combatir en las cercanías de Camargo, pero fue derrotado y regresó para ayudar a Villa. En Chihuahua hicieron todos los preparativos y anuncios como si fueran a regresarse a la sierra, empero, nuevamente engatusaron al enemigo, dado que Villa y Salazar tomaron, por enésima vez, Camargo y, a continuación, sorprendieron a todos con un ataque victorioso en Torreón el 19 de diciembre de 1916, en el que Salazar estuvo al frente de las tropas. Diez días más tarde, desalojaron la ciudad.

Con el propósito de visitar a su familia que se encontraba en Nuevo México, se separó de Villa y en el camino a la frontera fue asesinado el 19 de agosto de 1917, en el rancho de Nogales, a corta distancia de Casas Grandes, a manos de un grupo de campesinos de quienes no se sabe si lo confundieron con un asaltante o lo asesinaron pensando que llevaba dinero en las alforjas (El Paso del Norte, 15 de agosto de 1917).

El final de Salazar se asemeja, con mucho, al personaje de Demetrio Macías de la novela Los de abajo, de Mariano Azuela, quien, en sus últimos momentos, cerca de la frontera, duda sobre 
el porqué de su lucha, no la de 1906, sino la de 1916. Sabe que, eventualmente, no tendrá otro fin salvo morir en algún combate.

\section{REFERENCIAS}

Almada, F. R. (1964). La revolución en el estado de Chihuahua. México: INEHRM.

Alonso, A. M. (1995). Thread of Blood. Colonialismo, Revolution and Gender on Mexico's Northern Frontier. Tucson: Tucson University of Arizona Press.

Amaya, J. G. (2010). Madero y los auténticos revolucionarios de 1910. Hasta la Decena Trágica y fin del general Pascual Orozco (1946). Chihuahua: Biblioteca Chihuahuense.

Bartra, A. (1980). Regeneración 1900-1918. La corriente más radical de la Revolución mexicana de 1910 a través de su periódico de combate. México: Era.

Boletín Militar de la División del Norte, 7 y 21 de septiembre de 1912, n. ${ }^{\circ} 5$ y 7.

Bush, I. (1939). Gringo Doctor. Caldwell, Idaho: The Caxton Printers Ltd.

Caraveo, M. (1992). Crónica de la Revolución 1910-1929. México: Trillas.

Fabela, I. (1964). Documentos históricos de la Revolución mexicana. Revolución y régimen maderista. México: Jus.

Gerlach, A. (1968). Conditions along the Border - 1915. The Plan de San Diego. New Mexico Historical Review, XLII(3), 195-212. Hardy, B. C., \& Seymour, M. (1997). The Importation of Arms and the 1912 Mormon "Exodus" from Mexico. New Mexico Historical Review, 72, October, 297-318.

Jaurrieta, J. M. (1997). Con Villa, memorias de campaña 1910-1920. México: Conaculta.

Katz, F. (1999). Pancho Villa. México: Era.

Lloyd, J. D. (1987). El proceso de modernización capitalista en el noroeste de Chihuahua, 1880-1910. México: Universidad Iberoamericana. 
José Inés Salazar, una vida en la frontera duRAnte la ReVoludión...

---- (2001). Cinco ensayos sobre cultura material de rancheros y medieros del noroeste de Chihuahua, 1886-1910. México: Universidad Iberoamericana.

Lomnitz, C. (2010). Por mi espíritu hablará el nacionalismo revolucionario (Arqueología de la unidad nacional). Nexos, 386. Recuperado de: https://www.nexos.com.mx/ ?p=13506

Mendoza Soriano, R. José Inés Salazar (1878-1917). Semblanza de un guerrillero (inédito).

Mercado, S. R. (1916). Revelaciones históricas. Las Cruces, Nuevo México: [s.e.].

Meyer, M. C. (1984) El rebelde del norte. Pascual Orozco y la revolución (Serie de Historia Moderna y Contemporánea 16). México: UNAM.

Mundt, M. N. (1991). Revolution and Reaction: The Mexico North Western Railway Company during the 1912 Pascual Orozco Rebellion (tesis). Las Cruces: New Mexico State University.

Olea Arias, H. (1960). Apuntes históricos de la revolución, 19101911. Chihuahua: [s.e.].

Paulsen, G. E. (1983). Reaping the Whirlwind in Chihuahua: the Destruction of the Minas de Corralitos, 1911-1912. The New Mexico Historical Review, 58(3), 253-270.

Pierson Kerig, D. (1975). Luther T. Ellsworth: US Consul on the Border during the Mexican Revolution. Texas: Texas Western Press.

Resendi, S. F. (1912). La revolución actual. Sus causas y tendencias. Sus triunfos y fracasos. México: Imprenta de la Viuda de Charles Bouret.

Salazar, R. (1972). Las pugnas de la gleba. Los albores del movimiento obrero México. México: PRI.

Sánchez Lamego, M. A. (1976). Historia militar de la Revolución mexicana en la época maderista. Tomo I. México: INEHRM.

Sutherland Grant, J. (1991). Revolution and Rebellion: the Mormon Colonies of Northwestern Chihuahua (tesis). New Mexico State University.

Terrazas, S. (1984). El verdadero Pancho Villa. México: Era. 
Valadés, J. C. (2010). Jesús María Rangel: el brazo armado del magonismo fronterizo. México: Partido de la Revolución Democrática/Brigada Cultural "Para Leer en Libertad".

\section{PERIÓDICOS}

El Diario, Ciudad de México.

El Imparcial, Ciudad de México.

El Paso Herald, El Paso, Texas.

El Paso Morning Times, El Paso, Texas.

El Paso del Norte, El Paso, Texas.

El Siglo XX, El Paso, Texas.

\section{ARCHIVOS}

Archivo Francisco I. Madero. Microfilm, INAH, 22 rollos.

Dispatches from United States Consuls in Chihuahua, 1830-1906. National Archives and Records Service. National Archives Microfilm (1964).

Records of the Immigration and Naturalization Service. Serie A: Subject Correspondence Files. Part 2: Mexican Immigration, 1906-1930. University Publications of America. Bethesda, Maryland, 17 rollos. 